\title{
HAMBUR BALIK AKUSTIK PERMUKAAN SUBSTRAT DASAR PERAIRAN MENGGUNAKAN ECHOSOUNDER BIM TUNGGAL
}

\author{
Surface Backscattering Strength of Seabed Substrate Using Single Beam Echosounder
}

\author{
Baigo Hamuna ${ }^{1}$, Lisiard Dimara ${ }^{1}$, Sri Pujiyati ${ }^{2}$, Nyoman Metta N. Natih ${ }^{2}$ \\ ${ }^{1}$ Program Studi Ilmu Kelautan, FMIPA UNCEN, Jayapura, 99351, Indonesia \\ ${ }^{2}$ Departemen Ilmu dan Teknologi Kelautan, FPIK IPB, Bogor, 16680, Indonesia \\ Email: bhamuna@yahoo.com.sg
}

\begin{abstract}
ABSTRAK
Penelitian ini bertujuan untuk menganalisis nilai hambur balik permukaan dasar perairan berupa pasir dan lumpur. Echosounder bim tunggal Simrad EK15 frekuensi 200 $\mathrm{kHz}$ digunakan untuk perekaman hambur balik akustik permukaan dasar perairan. Pengambilan data dilakukan pada bulan tanggal 29 April - 2 Mei 2017 yang berlokasi di perairan Teluk Yos Sudarso, Kota Jayapura Provinsi Papua. Pengambilan contoh substrat digunakan untuk data validasi menggunakan sedimen grab. Hasil penelitian ini menggambarkan nilai rata-rata hambur balik permukaan substrat perairan pasir bervariasi antara $-37.48 \mathrm{~dB}$ sampai $-36.03 \mathrm{~dB}$, dan lumpur bervariasi antara $-46.98 \mathrm{~dB}$ sampai -45.15 dB. Hal ini juga menunjukkan bahwa substrat pasir memiliki tingkat kekerasan dan ukuran butir yang lebih besar dibandingkan jenis substrat lumpur substrat. Secara akustik, nilai hambur balik permukaan pasir akan lebih tinggi dibandingkan lumpur.
\end{abstract}

Kata kunci: Hambur Balik Permukaan, Pasir, Lumpur, Echosounder Bim Tunggal

\begin{abstract}
The objectives of this research are to analyze the surface backscattering strength of seabed. The single beam echosounder Simrad EK15 with $200 \mathrm{kHz}$ of frequencies was used for recordings of seabed acoustic backscattering. Data collection was conducted in April 29 - Mei 22017 which located in the Yos Sudarso Bay, Jayapura, Papua Province. Sampling substrate was taken for ground truth data using sediment grab. The results show that average value of surface backscattering strength of sand varied between $-37.48 \mathrm{~dB}$ up $-36.03 \mathrm{~dB}$, and mud varied between $-46.98 \mathrm{~dB}$ up $-45.15 \mathrm{~dB}$. It shows also that sand has a high substrate roughness, hardness, and grain size larger than the type of mud substrate. In acoustic backscattering values of sand were greater than mud.
\end{abstract}

Key words: Surface Scattering, Sand, Mud, Single Beam Echosounder

\section{PENDAHULUAN}

Teknologi hidroakustik memanfaatkan pencarian bawah laut dengan suara yang kuat untuk mendeteksi, mengamati dan menghitung parameter fisik dan biologi. Teknologi hidroakustik merupakan metode yang populer digunakan selama bertahun-tahun dalam survei sumber daya perikanan. Penelitian di bidang hidroakustik terus mengalami perkembangan yang signifikan.

Berdasarkan teori dan formula hidroakustik, teknik ini sekarang telah dimanfaatkan untuk melakukan survei klasifikasi dan pemetaan dasar perairan. Dimana dasar perairan memiliki komposisi yang sangat kompleks mulai dari substrat berukuran kecil sampai batubatuan seperti pasir, lumpur, lempung, karang dan patahan karang. Metode 
hidroakustik mampu melakukan pengukuran terhadap besar kecilnya pantulan dasar perairan dari berbagai tipe partikel. Gelombang akustik yang terjadi pada permukaan antara kolom air dan dasar laut yang mencakup pantulan dan pembauran pada daerah tersebut dan transmisi pada medium kedua. Proses ini secara umum ditentukan oleh beda impedansi akustik antara kedua medium tersebut (Siwabessy, 2001).

Konsep scattering strength dimunculkan untuk mengkuantifikasi scattering yang berasal dari dasar laut maupun permukaan laut, sedangkan backscattering strength merujuk pada bagian dari gelombang akustik yang dipantulkan kembali ke arah pemancar pada sistem sonar monostatik (Urick, 1983). Kekuatan energi akustik yang dipantulkan dari dasar perairan menggunakan SBES telah digunakan untuk mengklasifikasikan jenis dasar perairan dalam Acoustics Discrimination System (ADS). Hasil kuantifikasi pantulan akustik dasar perairan menunjukkan adanya perbedaan energi pantulan balik akustik dari sedimen dasar perairan seperti pasir, lumpur dan lempung (Manik, 2012; Ningsih dkk., 2013). Selain itu, terdapat perbedaan kekuatan hambur balik permukaan antara substrat pasir dengan berbagai tipe pertumbuhan karang dan patahan karang (Hamuna dkk., 2014).

Salah satu instrumen dalam menentukan kuat hambur balik akustik adalah echounder bim tunggal. Echosounder bim tunggal merupakan instrumen hidroakustik yang paling sederhana yang hanya memancarkan bim tunggal untuk mendeteksi target yang dilaluinya. Walaupun memiliki keterbatasan dibandingkan echosounder lainnya, menurut Anderson dkk. (2008) terdapat beberapa kelebihan penggunaan echosounder bim tunggal untuk survei substrat dasar perairan yang meliputi ketersediaan alat dan telah digunakan secara luas, efisiensi dan prosedur pengolahan data yang standar, pengoperasian alat yang relatif mudah serta tingkat akurasi tinggi baik dalam resolusi maupun presisi hasil.

Penelitian ini bertujuan untuk menganalisis nilai hambur balik akustik permukaan dasar perairan, yang berupa pasir dan lumpur dengan menggunakan echosounder bim tunggal. Dengan mengetahui nilai hambur balik akustik dasar perairan, maka akan memberikan kemudahan dalam proses identifikasi substrat dasar perairan secara akustik tanpa harus melakukan pengambilan sampel dasar perairan. Hasil penelitian ini diharapkan dapat menjadi tambahan database nilai hambur balik akustik dasar perairan.

\section{METODE PENELITIAN}

\section{Waktu dan Lokasi}

Perekaman data akustik dilaksanakan pada tanggal 29 April - 2 Mei 2017 dengan lokasi di perairan Kota Jayapura Provinsi Papua. Lokasi pengambilan data terdiri dari 3 lokasi. Lokasi 1 terletak di perairan Muara Tami terdiri dari 5 stasiun yang mewakili substrat lumpur, lokasi 2 di perairan Enggros yang terdiri dari 2 stasiun yang mewakili substrat pasir, dan lokasi 3 di sekitar Pulau Kosong yang terdiri dari 3 stasiun yang mewakii substrat pasir (Gambar 1).

\section{Pengambilan Data}

Perekaman data akustik dilakukan menggunakan instrumen hidroakustik sistem bim tunggal SIMRAD EK15 (spesifikasi pada Tabel 1) yang dioperasikan pada tiap stasiun penelitian. Perekaman data akustik dilakukan secara stasioner pada kondisi kapal dalam keadaan diam selama 5 sampai 10 menit. Pengambilan contoh diusahakan tepat berada di bawah transducer menggunakan sedimen grab $(20 \times 20 \mathrm{~cm})$ yang ke-mudian contoh substrat dasar perairan tersebut disimpan dalam kantung plastik untuk dianalisis lebih lanjut. Tekstur substrat dan densitas dari substrat tersebut akan digunakan sebagai data in situ sekaligus sebagai data pembanding dari hasil data perekaman akustik. 


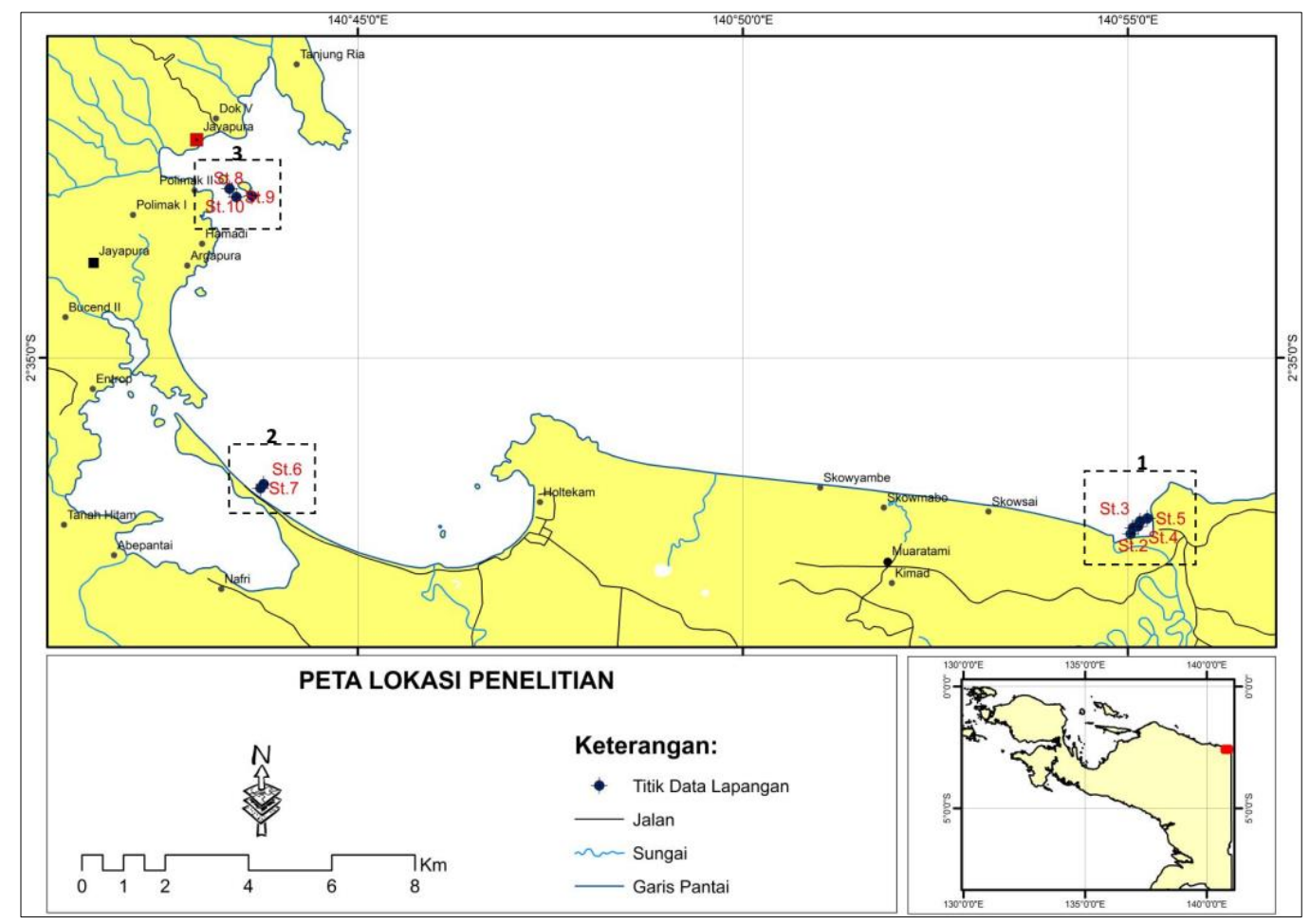

Gambar 1. Peta Lokasi Penelitian

Tabel 1. Spesifikasi SIMRAD EK15

\begin{tabular}{ll}
\hline \multicolumn{1}{c}{ Parameter } & \multicolumn{1}{c}{ Keterangan } \\
\hline Spesifikasi alat: & \\
Tipe transduser & Single beam \\
Frekuensi & $200 \mathrm{kHz}$ \\
Ping rate & $>40 \mathrm{~Hz}$ \\
Durasi pulsa & $80-1240 \mu \mathrm{s}$ \\
Lebar beam & $26^{\circ}$ \\
Output power & $45 \mathrm{~W}$ \\
& \\
Pengoperasian alat: & $1512,68 \mathrm{~m} / \mathrm{s}$ \\
Kecepatan suara & $($ lokasi 1$)$ \\
& $1545,87 \mathrm{~m} / \mathrm{s}$ \\
& $($ lokasi $2 \mathrm{dan} 3)$ \\
& \\
Panjang pulsa suara & $0.16 \mathrm{~ms}$ \\
& \\
Koefisien absorbsi & $0.01895 \mathrm{~dB} / \mathrm{m}$ \\
& $($ lokasi 1$)$ \\
& $0.05133 \mathrm{~dB} / \mathrm{m}$ \\
& $($ lokasi $2 \mathrm{dan} 3)$ \\
& $14.2 \mathrm{~dB}$ \\
\hline Transduser gain & \\
\hline
\end{tabular}

\section{Analisis Data}

Nilai hambur balik akustik dasar perairan $(S V)$ diekstrak menggunakan perangkat lunak Echoview 4.0. Data pantulan akustik dasar perairan yang diperoleh terdiri dari data pantulan pertama (E1) dan pantulan kedua (E2). Proses membedakan echo pantulan akustik dari beberapa tipe dasar perairan dilakukan dengan mengkuantifikasi sinyal echo yang diperoleh untuk menghasilkan suatu data berdasarkan nilai rata-rata pantulan akustik dasar perairan.

Dalam penelitian ini, nilai pantulan dasar perairan yang digunakan adalah nilai E1. Nilai E1 diolah menggunakan threshold minimal $-50.00 \mathrm{~dB}$ dan maksimum $0 \mathrm{~dB}$. Satuan dasar pencuplikan (Elementary Sampling Unit, ESU) yang digunakan pada proses pengolahan data untuk mengetahui nilai pantulan akustik dasar perairan adalah 100 ping. Ketebalan integrasi nilai E1 sebesar 0.2 meter yang disesuaikan dengan ketebalan pengambilan contoh substrat dasar perairan. Berdasarkan Johanesson dan Mitson (1983) bahwa prinsip dasar perhitungan nilai $S V$ perbandingan antara energi yang hasilkan oleh instrumen akustik dengan energi yang dipantulkan oleh objek yang dapat dinyatakan seperti persamaan berikut: 


$$
\mathrm{SV}[\mathrm{dB}]=10 \log \frac{\mathrm{I}_{\mathrm{r}}}{\mathrm{I}_{\mathrm{i}}}
$$

Dimana:

$\mathrm{I}_{\mathrm{r}}:$ energi hambur balik dari satuan volume objek pada jarak 1 meter

$\mathrm{I}_{\mathrm{i}}$ : energi yang mengenai objek

Surface backscattering strength $(S S)$ merupakan model yang dikembangkan untuk mengetahui nilai hambur balik dari permukaan dasar perairan. Berdasarkan persamaan dari Manik $d k k$. (2006) bahwa nilai $S V$ diperoleh dengan menghubungkan nilai surface backscattering coefficient (Ss) dan bottom volume backscattering coefficient (Sv) sesuai persamaan:

$\operatorname{Sv}=\frac{\mathrm{Ss} \Phi}{\Psi\left(\frac{\mathrm{c \tau}}{2}\right)}$

Pada puncak echo dasar perairan, nilai integrasi $\Psi \approx \Phi$ sehingga persamaan diatas menjadi (Manik dkk., 2006):

$\mathrm{SS}=\frac{\mathrm{c \tau}}{2} \mathrm{SV}$

Sehingga diperoleh nilai SS menggunakan persamaan berikut:

$\mathrm{SS}[\mathrm{dB}]=10 \log \mathrm{Ss}$
Dimana:

$\Phi:$ instantaneous equivalent beam angle for surface scattering

$\Psi$ : equivalent beam angle for volume scattering

$c$ : kecepatan suara

$\tau$ : panjang pulsa

\section{HASIL DAN PEMBAHASAN}

\section{Deteksi Dasar Perairan Secara Akustik}

Setiap pulsa akustik (echo) yang dipancarkan dan dipantulkan oleh target mengandung berbagai informasi. Masing-masing pantulan akan memberikan informasi yang berbeda sesuai dengan bentuk morfologi dasar perairan. Gambar 2 menyajikan echogram hasil perekaman akustik dasar perairan. Echogram merupakan tampilan grafis rekaman yang dihasilkan oleh echosounder, sebagai fungsi waktu, kekuatan echo dan waktu yang dibutuhkan echo untuk kembali. Pada echogram, skala warna menunjukkan sebaran nilai pantulan balik akustik target. Nilai piksel yang tinggi (berdasarkan warna) akan menunjukkan pemantulan dari target yang keras, sedangkan piksel yang rendah merupakan pengembalian yang lemah dan pembelokkan sinyal untuk target yang halus atau lembut. Menurut Preston dkk. (2000) bahwa echogram dapat memberikan informasi mengenai karakteristik dari target yang terdeteksi dan dapat berguna untuk klasifikasi dasar perairan.

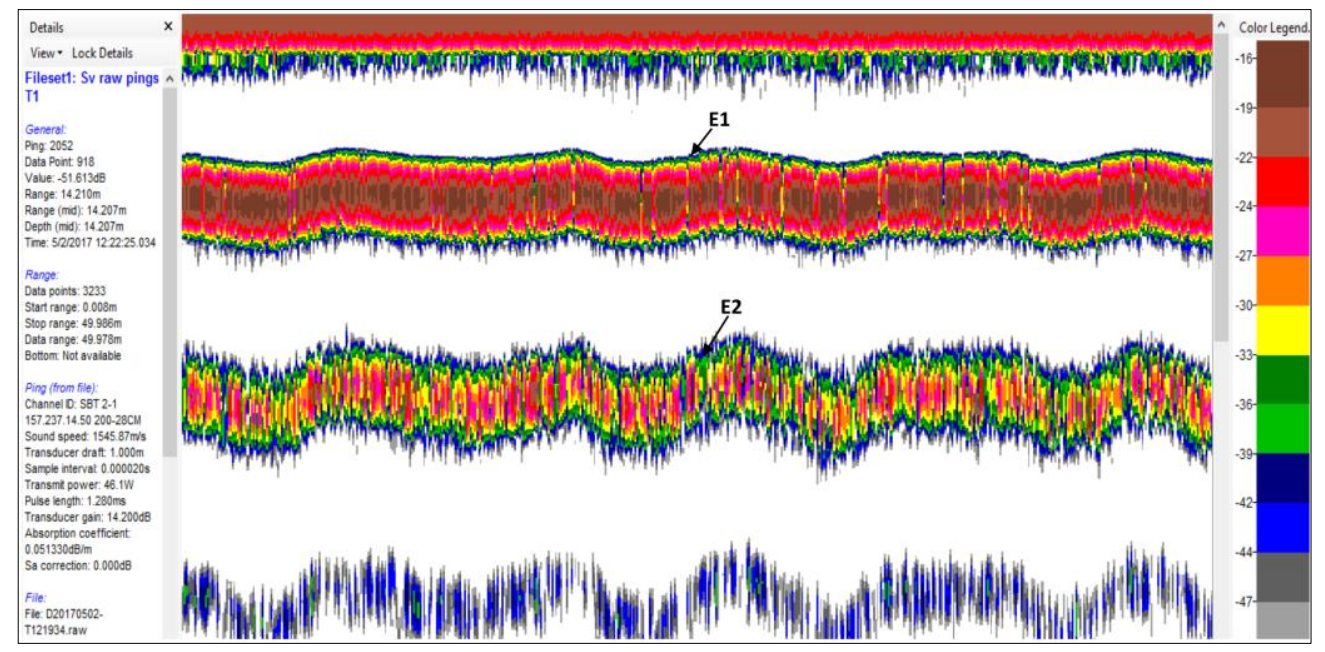

Gambar 2. Echogram hasil perekaman data akustik pada echoview dengan threshold -50 $\mathrm{dB}$ 
Gambar 3 menyajikan pola penjalaran sinyal akustik (echo envelope) yang terekam. Berdasarkan echo pantulan akustik yang terekam oleh transduser, pola perambatan sinyal akustik menggambarkan energi pantulan yang berasal dari dasar perairan yang berupa pantulan pertama (E1) dan pantulan kedua (E2). Puncak sinyal E1 lebih tinggi dibandingkan puncak sinyal E2. Puncakpuncak sinyal tersebut menunjukkan bahwa nilai pada E1 lebih tinggi dari E2. Menurut Penrose dkk. (2005), E1 merupakan gema yang berasal dari dasar perairan yang langsung diterima trans- duser, sedangkan E2 merupakan gema yang berasal dari dasar perairan kemudian kembali ke transduser tetapi dipantulkan oleh permukaan perairan atau kapal dan kembali ke dasar perairan dan kemudian dipantulkan kembali lagi ke transduser. Selain itu, terdeteksi juga zona near field yang dekat dengan permukaan perairan. Pada zona near field tersebut biasanya terjadi fluktuasi energi yang tidak stabil dari transduser, sehingga zona near field merupakan zona yang tidak ideal untuk dilakukan analisis pantulan akustik dari suatu target.

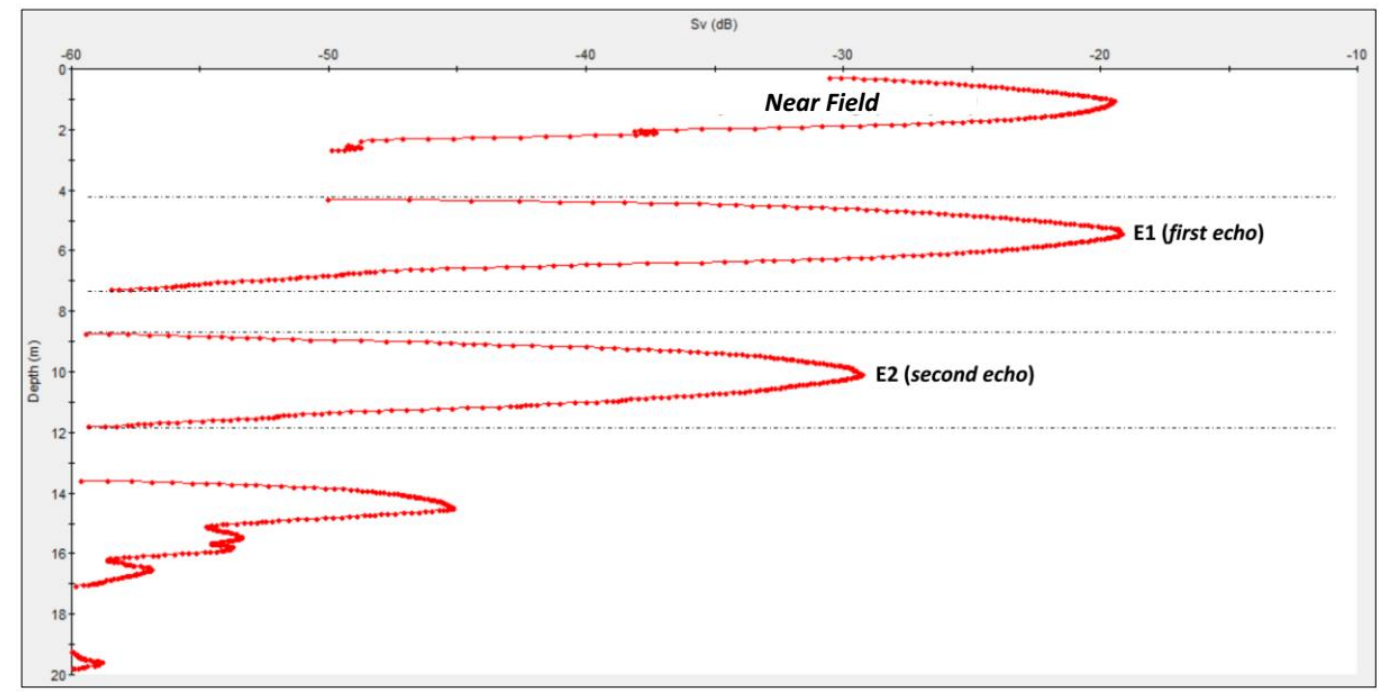

Gambar 3. Grafik energi hambur balik dasar perairan hasil rekaman akustik

Nilai piksel yang tinggi akan menunjukkan pemantulan dari target yang keras, sedangkan yang rendah merupakan pengembalian yang lemah dan pembelokkan sinyal untuk target yang halus atau lembut. Terlihat pada pada Gambar 2 dan Gambar 3 bahwa nilai E1 lebih tinggi dari nilai E2. Perbedaan tersebut dapat disebabkan oleh beberapa faktor antara lain berkurangnya energi pantulan karena pengaruh jarak, penyerapan energi oleh medium serta penyebaran energi pada medium. E1 terbentuk dari satu kali pantulan sedangkan E2 dapat terbentuk lebih dari satu kali pantulan (permukaan perairan dan dasar perairan) sehingga menyebabkan kehilangan energi lebih banyak akibat proses absorpsi pada E2.

Gambar 4 berikut menampilkan bentuk echogram dasar perairan yang berbeda dari hasil rekaman akustik dasar perairan yaitu substrat pasir dan substrat lumpur. Terdapat perbedaan warna echogram hasil rekaman akustik dari kedua tipe substrat tersebut. Kondisi ini disebabkan karena semakin keras atau lunaknya dasar perairan akan memberikan pengaruh terhadap intensitas pantulan akustik yang akan dikembalikan. 


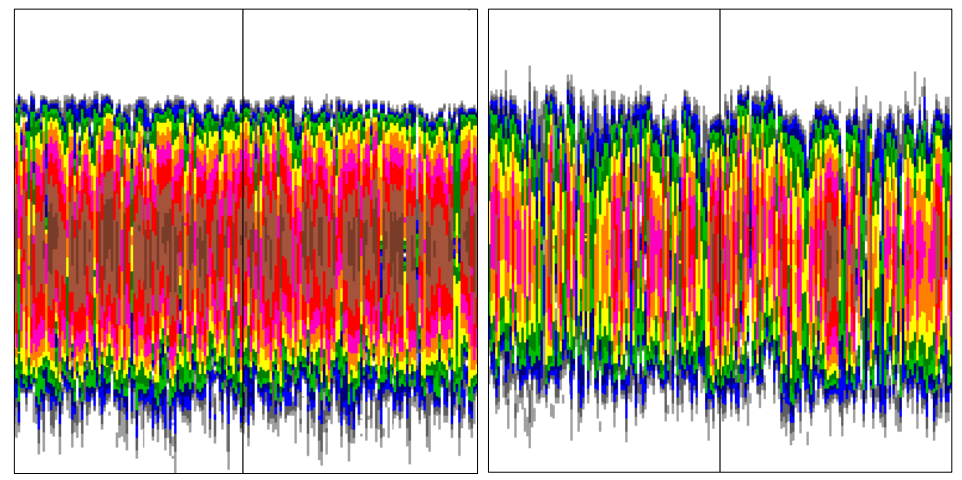

Gambar 4. Bentuk echogram (E1) substrat pasir (kiri) dan substrat lumpur (kanan) yang diolah dengan threshold $-50 \mathrm{~dB}$

\section{Surface Backscattering Strength}

Surface backscattering strength

(SS) merupakan perbandingan antara kekuatan intensitas suara yang dipantulkan dengan intensitas suara yang mengenai permukaan dasar perairan. Nilai
SS diperoleh dari puncak nilai echo pantulan permukaan dasar perairan. Tabel 2 berikut menyajikan hasil kuantifikasi nilai $S S$ substrat dasar perairan berupa pasir dan lumpur.

Tabel 2. Nilai rata-rata surface backscattering strength pasir dan lumpur pada stasiun penelitian

\begin{tabular}{clcccl}
\hline Stasiun & Lokasi & Kedalaman $(\mathbf{m})$ & SV $(\mathbf{d B})$ & SS $(\mathbf{d B})$ & Tipe substrat \\
\hline 1 & Muara Tami & 5.3 & -35.99 & -45.16 & Lumpur berpasir \\
2 & Muara Tami & 18.2 & -37.49 & -46.66 & Lumpur \\
3 & Muara Tami & 12.5 & -37.81 & -46.98 & Lumpur \\
4 & Muara Tami & 8.9 & -37.73 & -46.90 & Lumpur \\
5 & Muara Tami & 5.5 & -37.44 & -46.61 & Lumpur \\
6 & Enggros & 6.1 & -28.12 & -37.19 & Pasir halus \\
7 & Enggros & 4.5 & -28.40 & -37.48 & Pasir halus \\
8 & Pulau Kosong & 4.3 & -27.36 & -36.44 & Pasir kasar \\
9 & Pulau Kosong & 4.6 & -27.96 & -36.03 & Pasir kasar \\
10 & Pulau Kosong & 7.8 & -28.02 & -37.10 & Pasir kasar \\
\hline
\end{tabular}

Berdasarkan Tabel 2 diketahui bahwa nilai SS lebih rendah dibandingkan nilai SV. Hal ini disebabkan karena nilai SS merupakan nilai pantulan akustik dari permukaan dasar perairan saja, sedangkan SV merupakan nilai pantulan dasar perairan mulai permukaan sampai kedalaman 0,2 meter (tergantung pada kedalaman intergrasi). Perbedaan atau rasio selisih nilai SV dan SS pada lokasi penelitian berkisar antara $-9.17 \mathrm{~dB}$ hingga -9.08 dB, dimana selain disebabkan oleh tipe substrat, juga dipengaruhi parameter oseanografi perairan seperti suhu, Salinitas dan $\mathrm{pH}$ perairan yang digunakan sebagai parameter kalibrasi yang akan berpengaruh terhadap cepat rambat kece- patan suara dan koefisien absorbsi dalam perairan.

Hasil yang diperoleh menunjukkan bahwa terdapat perbedaan antara intensitas nilai SS yang dihasilkan oleh substrat dasar perairan pasir dan lumpur, begitupun antara pasir halus dengan pasir yang agak kasar. Hal ini menandakan bahwa tingginya tingkat penetrasi dan pantulan (refleksi) dasar perairan juga dipengaruhi oleh jenis sedimen. Keras atau lunaknya dasar perairan akan memberikan pengaruh terhadap intensitas pantulan yang dikembalikan, dimana dasar perairan yang keras memiliki pantulan yang lebih besar dari dasar perairan yang halus dan seterusnya (Siwabessy, 2001; Hamilton, 2001). Selain itu, permukaan dasar 
perairan yang kasar akan menyebabkan gema meluruh secara perlahan, sementara permukaan yang rata akan menyebabkan gema meluruh secara cepat (Boulton and Wyness, 2001).

Perbedaan ukuran butiran pasir atau substrat dasar perairan lainnya juga akan mempengaruhi intesitas nilai SS yang dipantulkan, dimana pasir ukuran butiran yang lebih besar akan memberikan nilai SS yang lebih tinggi dibandingkan pasir yang memiliki ukuran butiran yang lebih kecil. Substrat pasir yang kasar akan memiliki tingkat kekasaran, kekerasan dan ukuran diameter fraksi lebih besar dari pada substrat pasir halus, pasir berlumpur dan lumpur. Secara akustik semakin besar ukuran butir substrat semakin tinggi nilai SS yang terdeteksi. Hal ini sejalan dengan hasil penelitian Pujiyati dkk. (2010) dan Ningsih dkk. (2013) bahwa ukuran butiran substrat sangat mempengaruhi nilai hambur balik dasar perairan. Semakin besar ukuran butiran umumnya akan semakin besar tingkat kekasaran dan kekerasan dari tipe substrat dasar perairan sehingga dapat menghasilkan energi pantulan akustik yang lebih besar dari tipe substrat dengan ukuran butiran yang lebih kecil.

Hasil penelitian Ningsih dkk. (2013) mendapatkan nilai SS pasir berkisar antara $-12.97 \mathrm{~dB}$ sampai $-13.96 \mathrm{~dB}$ dan lumpur -19.25 dB sampai $-30.87 \mathrm{~dB}$, sedangkan penelitian Bemba (2011), SS pasir adalah $-22.67 \mathrm{~dB}$. Perbedaan nilai SS tersebut dengan hasil penelitian ini dapat disebabkan oleh penggunaan instrumen dan frekuensi yang berbeda, dimana kedua penelitian tersebut menggunakan echosounder Simrad EY 60 frekuensi 120 kHz. Menurut Chakraborty dkk. (2007) bahwa pada penggunaan dual frekuensi instrumen akustik akan memberikan hasil yang berbeda, frekuensi yang rendah akan memberikan nilai pantulan akustik yang lebih tinggi dibandingkan frekuensi yang tinggi pada dasar perairan yang sama. Faktor lain yang diduga dapat menyebabkan perbedaan nilai SS adalah kondisi perairan tersebut yang meliputi parameter fisik dan kimia perairan serta kondisi dasar perairan. Trend nilai SS substrat dasar perairan pasir dan lumpur hasil penelitian ini tidak berbeda dibandingkan dengan beberapa hasil penelitian yang telah dilakukan, dimana nilai SS substrat dasar perairan pasir selalu lebih tinggi dibandingkan SS dasar perairan lumpur.

\section{KESIMPULAN}

Secara akustik semakin besar ukuran butir substrat dasar perairan, maka semakin tinggi nilai hambur balik akustik yang terdeteksi. Nilai SS dasar perairan berupa pasir lebih tinggi dibandingkan SS dasar perairan berupa lumpur, dimana nilai SS dasar perairan pasir berkisar antara $-37.48 \mathrm{~dB}$ sampai $\quad-36.03 \mathrm{~dB}$ sedangkan nilai SS dasar perairan lumpur berkisar antara $-46.98 \mathrm{~dB}$ sampai 45.15 $\mathrm{dB}$.

\section{UCAPAN TERIMA KASIH}

Ucapan terima kasih penulis atas bantuan Hibah Penelitian Kerjasama Antar Perguruan Tinggi (PKPT) Kemenristekdikti Tahun Anggaran 2017. Artikel ini merupakan salah satu bagian dari hasil penelitian Aplikasi Hidroakustik Untuk Pemetaan Substrat Dasar Perairan dan Kaitannya Dengan Pendugaan Sebaran Habitat Ikan Demersal Di Perairan Teluk Yos Sudarso, Jayapura-Papua. Penulis juga ingin mengucapkan terima kasih kepada Balai Riset Perikanan Laut (BRPL) Jakarta yang telah meminjamkan instrumen Simrad EK15.

\section{DAFTAR PUSTAKA}

Anderson, J.T., Holliday, D.V., Kloser, R., Reid, D.G., Simard, Y., 2008. Acoustic Seabed Classification: Current Practice and Future Directions. ICES Journal of Marine Science, 65, 1004-1011.

Bemba, J., 2011. Identifikasi dan klasifikasi Lifeform Karang Menggunakan Metode Akustik. Tesis. Sekolah Pasca Sarjana, Institut Pertanian Bogor. Bogor. 
Boulton, B., Wyness, R., 2001. Annual Report: Sangachal Seabed Mapping Survey. London: BP.

Chakraborty, B., Mahale, V., Navelkar, G., Rao, B.R., Prabhudesai, R.G., Ingole, B., Janakiraman, G., 2007. Acoustic Characterization of Seafloor Habitats on the Western Continental Shelf of India. ICES Journal of Marine Science, 64, 551558.

Hamilton, L.J., 2001. Acoustics Seabed Classification System. Fishermans Bend, Victoria (AU): DSTO Aeronautical and Maritime Research Laboratory.

Hamuna, B., Pujiyati, S., Hestirianoto, T., 2014. Karakterisasi Pantulan Akustik Karang Menggunakan Echosounder Single Beam. Jurnal Integrasi, 6(2), 129-133.

Johannesson, K.A., Mitson, R.B., 1983. Fisheries Acoustic A Practical Manual for Acoustic Biomass Estimation. Roma: FAO Fisheries Technical Paper.

Manik, H.M., Furusawa, M., Amakasu, K., 2006. Measurement of Sea Bottom Surface Backscattering Strength by Quantitative Echosounder. Fisheries Science, 72, 503512.

Manik, H.M., 2012. Seabed Identification and Characterization Using Sonar. Advances in Acoustics and Vibration. Hindawi Publishing Corporation. Volume 2012, Article ID 532458, 5 pages.

Ningsih, E.N., Supriyadi, F., Nurdawati, S., 2013. Pengukuran dan Analisis Nilai Hambur Balik Akustik Untuk Klasifikasi Dasar Perairan Delta Mahakam. Jurnal Penelitian Perikanan Indonesia, 19(3), 139146.
Penrose, J.D, Siwabessy, P.J.W., Gavrilov, A., Parnum, I., Hamilton, L.J., Bickers, A., Brooke, B., Ryan, D. A., Kennedy, P., 2005. Acoustics Techniques for Seabed Classification. Technical Report 32, September 2005. Cooperative Research Centre for Coastal Zone Estuary and Waterway Management.

Preston, J.M, Rosenberger, A., Collins, W.T., 2000. Bottom Classification in Very Shallow Water. In: OCEANS 2000 MTS/IEEE Conference and Exhibition, 1563-1567.

Pujiyati, S., Hartati, S., Priyono, W., 2010. Efek Ukuran Butiran, Kekasaran, dan Kekerasan Dasar Perairan Terhadap Nilai Hambur Balik Hasil Deteksi Hydroakustik. Jurnal Ilmu dan Teknologi Kelautan Tropis, 2(1), 59-67.

Siwabessy, P.J.W., 2001. An Investigation of the Relationship between Seabed Type and Benthic and Bentho-Pelagic Biota Using Acoustic Techniques. Dissertation. The Curtin University of Technology, Australia.

Urick, R.J., 1983. Principles of Underwater Sound, 3rd ed. McGraw-Hill Publishing, New York. 